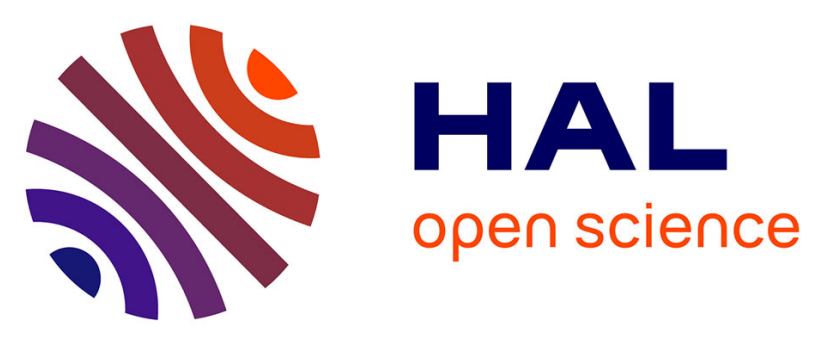

\title{
Patients with primary cervical dystonia have evidence of discrete deficits in praxis
}

\author{
Britt Sofie Hoffland, Dorinda Snik, Kailash P Bhatia, Elena Baratelli, Petra \\ Katschnig, Petra Schwingenschuh, Sebastian Crutch, Bart P van de \\ Warrenburg, Mark J Edwards
}

\section{To cite this version:}

Britt Sofie Hoffland, Dorinda Snik, Kailash P Bhatia, Elena Baratelli, Petra Katschnig, et al.. Patients with primary cervical dystonia have evidence of discrete deficits in praxis. Journal of Neurology, Neurosurgery and Psychiatry, 2010, 82 (6), pp.615. 10.1136/jnnp.2010.221937 . hal-00599479

\section{HAL Id: hal-00599479 https://hal.science/hal-00599479}

Submitted on 10 Jun 2011

HAL is a multi-disciplinary open access archive for the deposit and dissemination of scientific research documents, whether they are published or not. The documents may come from teaching and research institutions in France or abroad, or from public or private research centers.
L'archive ouverte pluridisciplinaire HAL, est destinée au dépôt et à la diffusion de documents scientifiques de niveau recherche, publiés ou non, émanant des établissements d'enseignement et de recherche français ou étrangers, des laboratoires publics ou privés. 


\section{Patients with primary cervical dystonia have evidence of discrete deficits in praxis}

Britt Sofie Hoffland ${ }^{1,2}$, Dorinda Snik ${ }^{1,2}$, Kailash P Bhatia ${ }^{1}$, MD, Elena Baratelli ${ }^{1}$, MD, Petra

Katschnig $^{1,4}, \mathrm{MD}$, Petra Schwingenschuh ${ }^{1,4}, \mathrm{MD}$, Sebastian Crutch ${ }^{3} \mathrm{PhD}$, Bart P van de

Warrenburg $^{2}$, MD, PhD, Mark J Edwards ${ }^{1}, \mathrm{PhD}$

1. Sobell Department of Motor Neuroscience and Movement Disorders, Institute of

Neurology, UCL, London WC1N 3BG, UK.

2. Department of Neurology, Radboud University Nijmegen Medical Centre, Nijmegen, The Netherlands.

3. Dementia Research Group, Institute of Neurology, UCL, London WC1N 3BG, UK.

4. Department of Neurology, Division of Special Neurology, Medical University Graz, Graz, Austria.

Address for Correspondence:Dr Mark J Edwards

NIHR Clinician Scientist

Sobell Department

Institute of Neurology

$\mathrm{UCL}$

Queen Square

London

WC1N 3BG

Tel: (+44) 2031080046

Fax:

Email: $\underline{\text { m.edwards@ion.ucl.ac.uk }}$ 
Running title: Dystonia and Apraxia

Key Words: dystonia, apraxia, sequence learning

Word count for text: 3110 


\section{$\underline{\text { Abstract }}$}

\section{Background}

Functional imaging and electrophysiological data from patients with primary dystonia reveal widespread abnormalities in brain areas associated with higher motor functions, but to date there has been little investigation of the functional consequences of these abnormalities. Our aim was to use a battery of tests of praxis, based on those tests used in routine clinical examination, to uncover evidence of higher motor dysfunction in patients with primary cervical dystonia.

\section{Methods}

We assessed praxis in 13 patients with primary cervical dystonia without hand involvement and 29 age and sex matched controls. We used a semi-quantitative praxis assessment which combined timed tests of meaningful and meaningless movements with copying of transitive and intratransitive hand movements and pantomime of tool use. Control tasks consisted of evaluation of motor speed, strength and a number of additional cognitive tasks.

\section{Results}

Patients made significantly more errors in copying meaningless gestures and were slow in the performance of meaningless sequences of hand movements. Copying meaningful gestures and performance of meaningful sequences of hand movements was normal.

\section{Conclusion}

This study has identified a discrete deficit in praxis in dystonia patients and suggests additional functional consequences from the widespread pathophysiological abnormalities seen in primary dystonia. 


\section{$\underline{\text { Introduction }}$}

Dystonia is a movement disorder characterized by involuntary muscle spasms that lead to sustained abnormal postures of the affected body part. By definition, patients with primary dystonia should have dystonia alone, without any other clinical signs. This rather narrow clinical phenotype is in stark contrast to the large and growing body of evidence regarding the pathophysiology of primary dystonia. Recently, some non-motor features of dystonia have been highlighted, for example an increased incidence of affective disorders [1-2]. Widespread dysfunction in multiple motor and non-motor areas is seen in primary dystonia, including areas that are typically categorized as part of the network supporting "higher" motor functions. For example, abnormalities in activation in prefrontal and sensorimotor cortices (which differ depending on the experimental setup) can be seen in primary dystonia [3-6]. These abnormalities are likely to be clinically relevant as they occur only during movement and their normalization (for example using repetitive transcranial magnetic stimulation) results in transient clinical improvement.

Given such widely distributed pathophysiological abnormalities in primary dystonia one might expect a more generalized impairment of complex higher level abilities involved in motor planning and execution in focal dystonia, in addition to the obvious impairment in motor execution resulting from involuntary muscle contractions. However, to date, there is little evidence in this regard. Considering the abnormalities previously demonstrated in parietal and premotor areas in primary dystonia, one could hypothesise that praxis (which is dependent on a distributed network that heavily relies on these areas) might be impaired in dystonia. The basal ganglia themselves are part of the "praxis network" given their role in sensorimotor integration and action sequencing.[7-9] However, lesion studies have previously demonstrated that apraxia is hardly ever seen as a consequence of basal ganglia lesions 
alone.[10] When clear apraxia is seen clinically in combination with dystonia, this is typically the consequence of combined basal ganglia and cortical dysfunction, for example in corticobasal degeneration.[10-11] However, we often do not routinely perform praxis testing in patients with typical primary dystonia, and nor is such data reported in the literature.

In this study we set out to perform a comprehensive assessment of praxis in patients with cervical dystonia. We deliberately chose this group of patients to ensure that any abnormalities on tests of praxis were not contaminated by the presence of hand dystonia. We chose to use a structured semi-quantitative praxis assessment consisting of a traditional praxis assessment and a sequential movement task that has previously been tested in patients with dementia and been found to be highly sensitive to deficits in praxis.[12]

\section{$\underline{\text { Methods }}$}

\section{Subjects}

Thirteen patients with a clinical diagnosis of primary cervical dystonia participated in this single session experiment. The patients were recruited from the movement disorders clinic at the National Hospital for Neurology and Neurosurgery. We set as exclusion criteria: 1) any involvement of the upper limbs by any disorder that could affect arm function, including dystonia (Burke Fahn Marsden score for the upper limb > 2), and 2) any use of medication that might affect limb function or attention (e.g. benzodiazepines). All patients were chronically treated with botulinum toxin, and all were assessed more than 3 months following their last injections. Informed consent was obtained from all participants and the study was given ethical approval by the Joint ethics committee of the Institute of Neurology and the National Hospital for Neurology and Neurosurgery. Twenty-nine historical control subjects were selected from control subjects previously reported in Crutch et al [12]. This selection 
was performed by taking all control subjects reported by Crutch et al who were within the age range of our cervical dystonia patients.

\section{Praxis Assessment}

This assessment is described in full in Crutch et al [12]. The qualitative praxis assessment consisted of: 1) a 10 item transitive movement task where subjects pantomimed the use of an object (e.g., hammer), 2) an 8 item meaningless intratransitive gesture production task (e.g., touch index finger and thumb) and 3) an 8 item meaningful intratransitive gesture production task (wave, salute). Up to three attempts to perform the action correctly were permitted. Performance was scored with 3,2,1 or 0 points depending whether it was correct on the first, second or third attempt or unsatisfactory on all occasions, respectively. A lower score therefore reflects poorer performance on the task. Tasks were performed for both dominant and non-dominant hands. Errors were classified as being content, temporal or spatial.

Content errors included: perseverations (the response includes all or part of a previously produced pantomime), a correctly produced pantomime of a different target (e.g. pantomiming playing a trombone for a target of a bugle) or a pantomime performed without the benefit of an imagined tool. A temporal error was defined as an error in the characteristic sequencing of a pantomimed action, an error in timing (increased, decreased or irregular rate of production) or an error in occurrence (incorrect multiplication or reduction of movement cycles). Spatial errors were defined as errors in the characteristic amplitude of a target pantomime, errors in the internal configuration of hand towards imagined target tool, body part as tool mistakes (e.g. patient uses index finger to brush teeth), errors in the external configuration of tool towards object receiving the action, or errors in the movement characteristic of the action (e.g. patient stabilizes for example the elbow and twists at the shoulder when asked to pantomime using a screwdriver). 
The quantitative praxis assessment consisted of two timed sequential movement tasks, one of three meaningful movements and one of three meaningless movements. The meaningful sequential movement task consisted of three meaningful actions; pulling a rope, pressing a door buzzer (button) and turning a handle. Figure 1a shows the correct actions associated with each component of the task. The meaningless sequential movement task was performed on a box with three differently shaped pads each of which had to be pressed in a different manner: flat palm of hand, fist, side of hand. The shape of the pads was such that they were designed to cue the correct movement. The correct actions associated with each component of this task are shown in Figure 1b.

After a "go" command subjects performed five complete cycles of each sequence as fast as possible while attempting to make the correct action for each component (Cycles 1-5). Subjects performed the test phase twice (Trial 1 and Trial 2) with their dominant hand and then twice with their non-dominant hand. During the first trial no feedback was given but if any error occurred during this first trial a verbal reminder of the correct movement(s) was given in the brief interval between Trial 1 and Trial 2 .

As control tasks, we assessed basic motor speed and hand strength by a single finger tapping test and a grip strength test. The finger tapping test consisted of a key that had to be pressed as many times as possible in 10 seconds. This procedure was then repeated 3 times to calculate an average tapping rate. Grip strength was assessed by using a Jamar hand dynamometer 5030J1. The mean pressure (lbs) exerted on two attempts with each hand was recorded. 


\section{Cognitive assessment}

All participants completed the National Adult Reading Test and the A cancellation test of psychomotor speed.[13-14] Eleven cervical dystonia patients were also administered the Graded Difficulty Arithmetic test, the Design Fluency test of visuospatial fluency and attention from the Delis-Kaplan Executive Function System, and an unpublished mental rotation test in which participants have to determine whether rotated pictures correspond to a left or right hand.[15-16]

\section{Statistics}

Data were analysed using SPSS for Windows (version 16.0). Distribution of data was assessed using standard tests of normality (Shapiro-Wilk), and if data were not normally distributed they were analysed using non-parametric tests (Mann-Whitney U test). Normally distributed continuous variables were analysed using independent sample t-tests. The preset level of significance was 0.05 .

\section{$\underline{\text { Results }}$}

Demographics and performance on tests of basic motor performance

Age, sex and handedness of the patients and controls are shown in table 1 . There were no significant differences found between patients and controls in terms of age $(\mathrm{t}(41)=0.10$;

$\mathrm{p}=0.86)$, proportion of male subjects $\left(X^{2}=0.20, \mathrm{p}>0.65\right)$ or handedness $\left(X^{2}=0.67, \mathrm{p}>0.4\right)$. There was no significant group difference in general intelligence estimated by the NART reading task (Nelson, 1982) $(\mathrm{t}(1.04)=40, \mathrm{p}>0.30)$. 
Table 1: Age, sex and handedness for patients and controls.

\begin{tabular}{|l|l|l|l|l|l|l|}
\hline Group & Number & $\begin{array}{l}\text { Mean } \\
\text { Age (SD) }\end{array}$ & $\begin{array}{l}\text { Percentage } \\
\text { of Males }\end{array}$ & $\begin{array}{l}\text { Percentage } \\
\text { of right } \\
\text { handers }\end{array}$ & $\begin{array}{l}\text { Fahn } \\
\text { Marsden } \\
\text { score } \\
\text { (SD) }\end{array}$ & $\begin{array}{l}\text { Estimated } \\
\text { general } \\
\text { intelligence }\end{array}$ \\
\hline $\begin{array}{l}\text { Dystonia } \\
\text { patients }\end{array}$ & 13 & $57.0 \pm 8.6$ & $31 \%$ & $92 \%$ & $3.45 \pm 2.0$ & $110.2 \pm 10.4$ \\
\hline Controls & 29 & $57.5 \pm 7.0$ & $38 \%$ & $83 \%$ & & $113.9 \pm 10.5$ \\
\hline
\end{tabular}

There were no significant differences between patients and controls in the tapping task (dominant hand: $\mathrm{t}(40)=-0.56 ; \mathrm{p}=0.58$; non-dominant hand: $\mathrm{t}(40)=-0.37 ; \mathrm{p}=0.71)$.

Comparison of dominant and non-dominant hand strength (dominant hand: $\mathrm{t}(37)=0.047$;

$\mathrm{p}=0.96$; non-dominant hand: $\mathrm{t}(37)=0.25 ; \mathrm{p}=0.80)$ between patient and controls did not reveal any significant differences.

\section{Copying gestures and pantomiming tool use}

Scores for all subjects in ability to copy meaningless and meaningful gestures and to pantomime tool use are shown in table 2. Scores for dominant and non-dominant hands are given separately. The maximum score for the meaningless and meaningful gesture copying was 24 and for pantomiming tool use was 30. Data of all three tasks were not normally distributed and therefore non-parametric tests were used to compare patients and controls. There were no significant differences between patients and controls in copying meaningful gestures (dominant hand: $Z=-0.56 ; p=0.58$; non-dominant hand: $Z=-1.23 ; p=0.21$ ) nor in pantomiming tool use (dominant hand: $Z=-0.69 ; p=0.49$; non-dominant hand: $Z=-0.29$; $\mathrm{p}=0.78$ ). However, patients made significantly more mistakes in copying meaningless gestures compared with controls for both dominant and non-dominant hands (dominant hand: $Z=-4.13 ; p<0.001 ;$ non-dominant hand: $Z=-2.37 ; p=0.018)$. 
Errors were classified as being content, temporal or spatial and were compared between patients and controls. There is no significant difference between the type of errors made between the control or patient group. For both groups the majority of mistakes were spatial (72.2\% vs. $71.4 \%)$ with temporal errors next most common (21.3\% and $24.7 \%)$.

Table 2: Performance of dystonia patients and controls on traditional praxis tasks.

\begin{tabular}{|c|c|c|c|c|c|c|}
\hline & \multicolumn{2}{|c|}{ Dystonia patients } & \multicolumn{2}{|l|}{ Controls } & \multicolumn{2}{|c|}{ Group differences } \\
\hline \multicolumn{7}{|c|}{ Traditional praxis assessments } \\
\hline & $\mathrm{D}$ & ND & $\mathrm{D}$ & ND & $\mathrm{D}$ & ND \\
\hline $\begin{array}{l}\text { Transitive gestures } \\
\text { (maximal score } 30 \text { ) }\end{array}$ & $29.31 \pm 0.9$ & $29.31 \pm 0.9$ & $29.00 \pm 1.3$ & $29.28 \pm 1.2$ & $\begin{array}{l}Z=-0.69 \\
p=0.49\end{array}$ & $\begin{array}{l}Z=-0.29 \\
p=0.78\end{array}$ \\
\hline $\begin{array}{l}\text { Meaningful } \\
\text { intratransitive } \\
\text { gestures } \\
\text { (maximal score 24) }\end{array}$ & $23.38 \pm 0.8$ & $23.31 \pm 0.8$ & $23.55 \pm 0.6$ & $23.59 \pm 0.6$ & $\begin{array}{l}Z=-0.56 \\
p=0.58\end{array}$ & $\begin{array}{l}Z=-1.23 \\
p=0.21\end{array}$ \\
\hline $\begin{array}{l}\text { Meaningless } \\
\text { intratransitive } \\
\text { gestures } \\
\text { (maximal score 24) }\end{array}$ & $22.00 \pm 1.0$ & $22.62 \pm 1.0$ & $23.55 \pm 1.0$ & $23.38 \pm 0.9$ & $\begin{array}{l}Z=-4.13 \\
p<0.001\end{array}$ & $\begin{array}{l}Z=-2.37 \\
p=0.018\end{array}$ \\
\hline $\begin{array}{l}\text { Total score } \\
\text { summing across } \\
\text { hands and tasks } \\
\text { (maximal score 156) }\end{array}$ & \multicolumn{2}{|l|}{$150 \pm 3.55$} & \multicolumn{2}{|l|}{$152 \pm 3.52$} & \multicolumn{2}{|l|}{$\begin{array}{l}\mathrm{Z}=-2.25 \\
\mathrm{p}=0.025\end{array}$} \\
\hline
\end{tabular}

\section{Performance on meaningful and meaningless sequence tasks}

Table 3 shows the completion time for the meaningful and meaningless sequence tasks for the dominant and non-dominant hands of patients and controls. These times are the mean of the two trials that subjects had with each task. These data were normally distributed and therefore were compared using independent samples $t$ tests. There were no differences found between the performance of controls and patients on the meaningful sequence task with either hand (dominant hand: $\mathrm{t}(40)=1.55 ; \mathrm{p}=0.13$; non-dominant hand: $\mathrm{t}(40)=-0.18 ; \mathrm{p}=0.86$ ) and nor with the meaningless sequence performed with the non-dominant hand $(\mathrm{t}(40)=-1.51$; $\mathrm{p}=0.14$ ). However, dystonia patients were significantly slower than controls on performance 
of the meaningless sequence task with their dominant hand $(\mathrm{t}(40)=-2.14 ; \mathrm{p}=0.039)$. Dystonia patients also made significantly more errors on the sequence tasks $(\mathrm{t}(40)=-2.94 ; \mathrm{p}=0.009)$.

Table 3: Completion time for the meaningful and meaningless sequence tasks.

\begin{tabular}{|l|l|l|l|l|l|l|}
\hline & \multicolumn{2}{|l|}{ Dystonia patients } & Controls & \multicolumn{2}{l|}{$\begin{array}{l}\text { Group } \\
\text { differences }\end{array}$} \\
\hline Sequential movement tasks & ND & $\mathrm{D}$ & $\mathrm{ND}$ & $\mathrm{D}$ & $\mathrm{ND}$ \\
\hline $\begin{array}{l}\text { Sequence completion } \\
\text { time (sec) }\end{array}$ & $\mathrm{D}$ & & & & & \\
\hline Meaningful sequence & $9.16 \pm 0.89$ & $9.38 \pm 1.48$ & $9.71 \pm 1.39$ & $9.30 \pm 1.34$ & $\mathrm{p}=0.13$ & $\mathrm{p}=0.86$ \\
\hline Meaningless sequence & $10.83 \pm 2.31$ & $10.18 \pm 2.16$ & $9.38 \pm 1.91$ & $9.27 \pm 1.65$ & $\mathrm{p}=0.039$ & $\mathrm{p}=0.14$ \\
\hline $\begin{array}{l}\text { Total errors sequence } \\
\text { tasks }\end{array}$ & $1.77 \pm 1.4$ & $0.55 \pm 0.9$ & & $\mathrm{p}=0.009$ \\
\hline
\end{tabular}

Table 4 shows data for patients and controls comparing time taken to complete the first and the last movement sequence of the meaningful and meaningless sequence tasks with their dominant and non-dominant hand. Controls showed a significant speeding up of performance between the first and last movement sequence of the meaningful movement task with their dominant hand $(\mathrm{t}(28)=2.20 ; \mathrm{p}=0.037)$. A similar effect was found in patients $(\mathrm{t}(12)=2.98$; $\mathrm{p}=0.012$ ). Controls also showed a significant speeding up with their non-dominant hand on the meaningful sequence task $(\mathrm{t}(28)=4.44 ; \mathrm{p}<0.001)$, but a similar effect was not observed in patients $(\mathrm{t}(12)=0.24 ; \mathrm{p}=0.81)$. Controls significantly speeded up performance of the meaningless sequence task with their dominant hand $(\mathrm{t}(28)=3.96 ; \mathrm{p}<0.001)$, but again patients did not $(\mathrm{t}(12)=0.51 ; \mathrm{p}=0.62)$. There was no significant difference in first and last sequence completion time for controls nor patients in the meaningless sequence task when this task was performed with their non dominant hand (controls $\mathrm{t}(28)=0.87 ; \mathrm{p}=0.39$; patients $\mathrm{t}(12)=-0.23$; $\mathrm{p}=0.83)$. 
Table 4: Sequence completion time for patients and controls.

\begin{tabular}{|l|l|l|l|l|l|l|}
\hline & \multicolumn{2}{|l|}{$\begin{array}{l}\text { Sequence completion } \\
\text { time first sequence, } \\
\text { first trial }\end{array}$} & $\begin{array}{l}\text { Sequence completion } \\
\text { time last sequence, } \\
\text { second trial }\end{array}$ & \multicolumn{2}{l|}{$\begin{array}{l}\text { Comparison of } \\
\text { sequence completion } \\
\text { time }\end{array}$} \\
\hline $\begin{array}{l}\text { Sequential } \\
\text { movement task }\end{array}$ & Patients & Controls & Patients & Controls & Patients & Controls \\
\hline $\begin{array}{l}\text { Meaningful } \\
\text { D }\end{array}$ & $2.14 \pm 0.32$ & $2.12 \pm 0.51$ & $1.78 \pm 0.38$ & $1.93 \pm 0.33$ & $\mathrm{p}=0.012$ & $\mathrm{p}=0.037$ \\
\hline $\begin{array}{l}\text { Meaningful } \\
\text { ND }\end{array}$ & $1.92 \pm 0.25$ & $2.03 \pm 0.35$ & $1.89 \pm 0.42$ & $1.81 \pm 0.31$ & $\mathrm{p}=0.81$ & $\mathrm{p}<0.001$ \\
\hline $\begin{array}{l}\text { Meaningless } \\
\text { D }\end{array}$ & $2.17 \pm 0.69$ & $1.92 \pm 0.35$ & $2.08 \pm 0.54$ & $1.76 \pm 0.41$ & $\mathrm{p}=0.62$ & $\mathrm{p}<0.001$ \\
\hline $\begin{array}{l}\text { Meaningless } \\
\text { ND }\end{array}$ & $2.05 \pm 0.51$ & $1.87 \pm 0.39$ & $2.10 \pm 0.66$ & $1.82 \pm 0.38$ & $\mathrm{p}=0.83$ & $\mathrm{p}=0.39$ \\
\hline
\end{tabular}

\section{Cognitive tasks}

Patients performed within the normal range on the A cancellation task (standardized age matched population mean and standard deviation: $20.5 \pm 6.5$, patients: $20.16 \pm 2.7)$. There were no correlations between score on this task and any of the praxis tasks. On the additional cognitive assessments, patients scored within the standardized normal range on both calculation (standardized age matched population mean and standard deviation raw score $11.95 \pm 5.09$, patients $13.83 \pm 4.15$ ) and design fluency (normal mean and standard deviation scaled score $10 \pm 3$, patients $12.81 \pm 2.96$ ), and there were no correlations between the scores on these tasks and any of the praxis tasks. Normative data on the mental rotation task are not available, but again there were no significant correlations between praxis scores and scores on this task (all $\mathrm{p}>0.3)$.

\section{$\underline{\text { Discussion }}$}

This study was based on the hypothesis that the widespread pathophysiological abnormalities within the complex motor network revealed by functional imaging and electrophysiological studies in primary dystonia might be reflected by abnormalities on clinical tests of praxis. In line with this prediction, we found that patients with primary cervical dystonia demonstrated 
significant but subtle impairments on production of meaningless gestures compared to age matched controls. Dystonic patients were also slower on production of a meaningless sequence of movements, and were not able to speed up their performance of these movements over repeated trials. These deficits were not associated with poorer performance than controls on assessments of basic motor performance and cognitive function.

Dystonia patients were not impaired on production of meaningful intratransitive gestures nor on pantomiming object use despite their poorer performance on copying meaningless gestures during the traditional praxis assessment. Disturbance of gesture/movement production in dystonia therefore appears to be specific for production of novel movements. The imitation of meaningless and novel gestures differs from the other traditional praxis tasks, as there are no representations in long-term memory and imitation of these gestures is achieved by a dedicated path independent of semantic memory. The term 'visuo-imitative apraxia' has been coined for apraxic patients with a selective deficit in imitating meaningless gestures.[17-18] Functional imaging studies suggest that praxis errors in these patients arise at a conceptual stage from either a general inability to temporarily store and/or manipulate spatial relationships in visuo-spatial working memory or from an impairment of the body schema (on-line representation of the current configuration of the body).[17,19-21] Interestingly, previous research has indicated a slowness in the mental rotation of corporeal objects in patients with cervical dystonia, a task strictly linked to this concept.[22] We, however, could not find a significant correlation between performance on the additional simple mental rotation task and any praxis task.

We also identified a particular pattern of impairment in sequence learning in dystonia patients. In contrast to controls, dystonia patients failed to improve their motor sequence 
production time for both the meaningful sequence performed with the non-dominant hand, and the meaningless sequence performed with the dominant hand. This finding cannot be ascribed to a general psychomotor slowing, as there is no overall difference in speed on the meaningful task and patients were able to speed up significantly in producing meaningful sequence with the dominant hand. Impairment in sequence learning in DYT1 gene carriers has been previously reported and is accompanied by a different pattern of brain activation during learning with an overactivation of the cerebellum.[23-24] Sequences in our study were however easy, and were cued. In our study, it seems as though movement familiarity affected task performance of patients and controls. In normal subjects, PET studies have provided evidence for a non-unitary mechanism of motor learning where the SMA, primary sensorimotor cortex, basal ganglia (mid-posterior putamen) and the cerebellum are mainly involved in the execution of automatic, overlearned sequential movements. In a more difficult or newly learned sequence the prefrontal, premotor and posterior parietal cortices plus the anterior part of the caudate/putamen also become activated because of the attention, integration of multimodal information and working memory processes that the task requires. $[9,25]$ We speculate that the impairments of dystonia patients on sequence tasks that involved production of novel or unusual hand movements (meaningless sequences) reflect difficulties in higher level motor planning and learning.

We used historical control subjects rather than assessing new controls, which might potentially create problems with standardization of the testing between controls and patients. However, the scoring used for the various tests is simple and in the case of the sequence task is computerized, and therefore we do not think that the use of historical control subjects is likely to have biased results significantly. The qualitative praxis tests in this study were always scored by the same two raters. 
The praxis deficits that we have uncovered in cervical dystonia patients without clinical involvement of the hand by dystonia are mild and are probably unlikely to have any major functional consequences for the patients. However, when extrapolating our findings in cervical dystonia to patients with hand dystonia, one might speculate that these patients could have more significant problems with praxis contributing to their disability. We have often been struck clinically by the extreme difficulty in writing experienced by some patients with primary writing dystonia in the absence of objectively severe abnormal postures of the limb. Such patients use phrases such as "my pen just won't move" or "my hand just stops writing" which in the absence of marked abnormal postures appear to describe a more complex, "higher" motor dysfunction. This motor aspect of dystonia is however not routinely examined and any deficits caused by apraxia would be hard to disentangle from the disability caused by abnormal postures of the fingers and hand.

The previous success of sensory and motor training programs to improve function in patients with focal hand dystonia may result in part from modulation of malfunctioning praxis networks.[26-27] These praxis networks may have an intrinsic ability to change, perhaps reflecting the more functional rather than structural substrate for primary dystonia. We suggest that it may be of interest to further investigate praxis deficits in patients with dystonia, for example with imaging studies, and to explore how we may be able to benefit patients by incorporating this knowledge into therapeutic developments. 


\section{$\underline{\text { Footnotes }}$}

Competing interests: None

Financial Disclosures: BPvdW and BSH are supported by a grant from the Prinses Beatrix

Fonds. DS is supported by a scholarship from the Prinses Beatrix Fonds. MJE is supported by a grant from the National Institutes of Health Research. SC is supported by an Alzheimer's Research Trust Research Fellowship.

Ethics approval: This project was approved by the Joint Ethics Committee of the Institute of Neurology and the National Hospital for Neurology and Neurosurgery

\section{Copyright license statement}

The Corresponding Author has the right to grant on behalf of all authors and does grant on behalf of all authors, an exclusive licence (or non-exclusive for government employees) on a worldwide basis to the BMJ Group and co-owners or contracting owning societies (where published by the BMJ Group on their behalf), and its Licensees to permit this article (if accepted) to be published in Journal of Neurology, Neurosurgery \& Psychiatry and any other BMJ Group products and to exploit all subsidiary rights, as set out in our licence. 


\section{$\underline{\text { Appendices }}$}

\section{Legends to Figures and Tables}

Figure 1a: The meaningful sequential movement task of the quantitative praxis assessment consisted of three meaningful actions; pulling a rope, pressing a door buzzer (button) and turning a handle.

Figure 1b: The meaningless sequential movement task of the quantitative praxis assessment was performed on a box with three differently shaped pads that were designed to cue the movement. The pads had to be pressed in the following manner; flat palm of hand, fist, side of hand.

Table 1: Subject characteristics are shown in this table. Patient and controls completed the National Adult Reading Task to estimate general intelligence.

Table 2: This table shows the performance of dystonia patients and controls on traditional praxis task. Scores on praxis assessment are stated as raw scores with standard deviation. Group comparison test statistics are shown. $\mathrm{D}=$ dominant hand $\mathrm{ND}=$ non dominant hand.

Table 3: This table illustrates the performance of dystonia patients and controls on the quantitative praxis assessment. The mean completion time of two trials for the meaningful sequence and meaningless sequence tasks are stated together with group comparison test statistics. Completion time is expressed in seconds and stated with standard deviation. 
The total errors made on these sequence tasks are also demonstrated. $\mathrm{D}=$ dominant hand $\mathrm{ND}=$ non dominant hand.

Table 4: Sequence completion time for patients and controls comparing the time to complete the first sequence of the first trial with the last sequence of the second trial is illustrated in this table. Completion time is expressed in seconds and stated with standard deviation. $\mathrm{D}=$ dominant hand $\mathrm{ND}=$ non dominant hand. 


\section{$\underline{\text { References }}$}

1. Koukouni V, Martino D, Arabia G, Quinn NP, Bhatia KP. The entity of young onset primary cervical dystonia. Mov Disord 2007;22:843-7.

2. Fabbrini G, Berardelli I, Moretti G, Pasquini M, Bloise M, Colosimo C, Biondi M, Berardelli A. Psychiatric disorders in adult-onset focal dystonia: a case-control study. Mov Disord 2010;25:459-65.

3. Ceballos-Baumann AO, Passingham RE, Warner T, Playford ED, Marsden CD, Brooks DJ. Overactive prefrontal and underactive motor cortical areas in idiopathic dystonia. Ann.Neurol. 1995;37:363-72.

4. Ibanez V, Sadato N, Karp B, Deiber MP, Hallett M. Deficient activation of the motor cortical network in patients with writer's cramp. Neurology 1999;53:96-105.

5. Odergren T, Stone-Elander S, Ingvar M. Cerebral and cerebellar activation in correlation to the action-induced dystonia in writer's cramp. Mov Disord. 1998;13:497-508.

6. Tempel LW, Perlmutter JS. Abnormal cortical responses in patients with writer's cramp. Neurology 1993;43:2252-7.

7. Graziano MS, Gross CG. A bimodal map of space: somatosensory receptive fields in the macaque putamen with corresponding visual receptive fields. Exp.Brain Res. 1993;97:96-109.

8. Pastor MA, Day BL, Macaluso E, Friston KJ, Frackowiak RS. The functional neuroanatomy of temporal discrimination. J.Neurosci. 2004;24:2585-91.

9. Catalan MJ, Honda M, Weeks RA, Cohen LG, Hallett M. The functional neuroanatomy of simple and complex sequential finger movements: a PET study. Brain 1998;121:25364.

10. Pramstaller PP, Marsden CD. The basal ganglia and apraxia. Brain 1996;119:319-40. 
11. Gross RG, Grossman M. Update on apraxia. Curr.Neurol.Neurosci.Rep. 2008;8:490-6.

12. Crutch SJ, Rossor MN, Warrington EK. The quantitative assessment of apraxic deficits in Alzheimer's disease. Cortex 2007;43:976-86.

13. Nelson, HE. The National Adult Reading task (NART): National Adult Reading Test. NFER-Nelson, Windsor, UK 1982.

14. Willison JR, Warrington EK. Cognitive retardation in a patient with preservation of psychomotor speed. Behav.Neurol. 1992;5:113-6.

15. Jackson M, Warrington EK. Arithmetic skills in patients with unilateral cerebral lesions. Cortex 1986;22:611-20.

16. Delis DC, Kramer JH, Kaplan E, Holdnack J. Reliability and validity of the DelisKaplan Executive Function System: an update. J.Int.Neuropsychol.Soc. 2004;10:301-3.

17. Goldenberg G, Hagmann S. The meaning of meaningless gestures: a study of visuoimitative apraxia. Neuropsychologia 1997;35:333-41.

18. Mehler MF. Visuo-imitative apraxia. Neurology 1987;37:129.

19. Chaminade T, Meltzoff AN, Decety J. An fMRI study of imitation: action representation and body schema. Neuropsychologia 2005;43:115-27.

20. Goldenberg G. Matching and imitation of hand and finger postures in patients with damage in the left or right hemispheres. Neuropsychologia 1999;37:559-66.

21. Schwoebel J, Buxbaum LJ, Coslett HB. Representations of the human body in the production and imitation of complex movements. Cognitive Neuropsychology 2004;21:285-98.

22. Fiorio M, Tinazzi M, Ionta S, Fiaschi A, Moretto G, Edwards MJ, Bhatia KP, Aglioti SM. Mental rotation of body parts and non-corporeal objects in patients with idiopathic cervical dystonia. Neuropsychologia 2007;45:2346-54. 
23. Carbon M, Ghilardi MF, Argyelan M, Dhawan V, Bressman SB, Eidelberg D. Increased cerebellar activation during sequence learning in DYT1 carriers: an equiperformance study. Brain 2008;131:146-54.

24. Ghilardi MF, Carbon M, Silvestri G, Dhawan V, Tagliati M, Bressman S, Ghez C, Eidelberg D. Impaired sequence learning in carriers of the DYT1 dystonia mutation. Ann.Neurol. 2003;54:102-9.

25. Grafton ST, Hazeltine E, Ivry R. Functional Mapping of Sequence Learning in Normal Humans. Journal of Cognitive Neuroscience 1995;7:497-510.

26. Zeuner KE, Bara-Jimenez W, Noguchi PS, Goldstein SR, Dambrosia JM, Hallett M. Sensory training for patients with focal hand dystonia. Ann.Neurol. 2002;51:593-8.

27. Zeuner KE, Molloy FM. Abnormal reorganization in focal hand dystonia--sensory and motor training programs to retrain cortical function. NeuroRehabilitation. 2008;23:4353. 


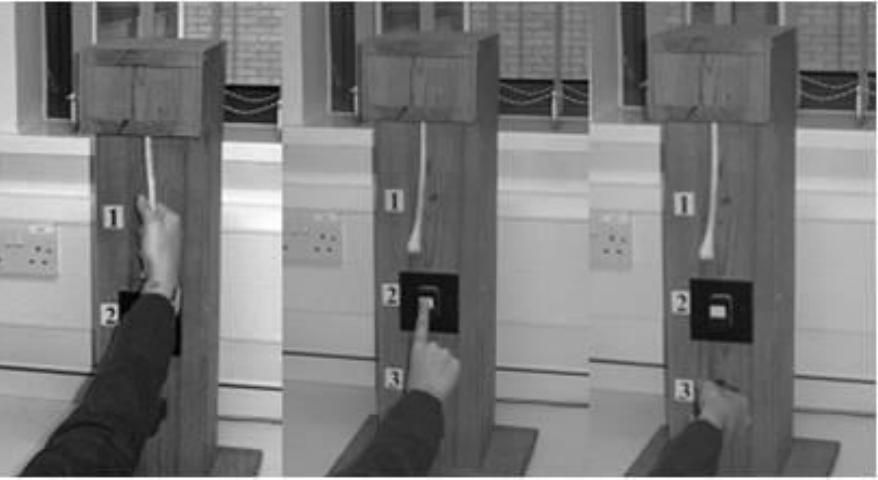




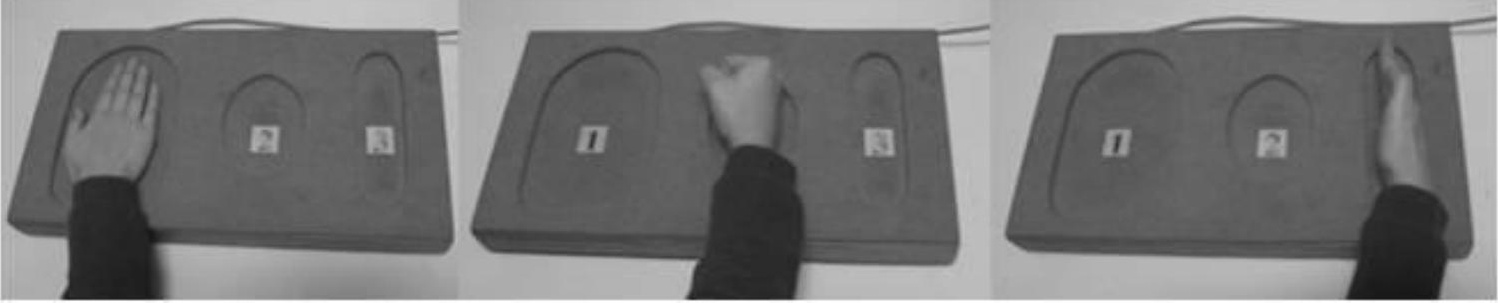

